\title{
Isothermal Oxidation Behavior of Plasma Sprayed MCrAIY Coatings
}

\author{
Dowon Seo ${ }^{1}$ and Kazuhiro Ogawa ${ }^{2}$ \\ ${ }^{1}$ Dept. of Mechanical Eng., Toyohashi University of Technology, Toyohashi, \\ ${ }^{2}$ Fracture \& Reliability Research Institute, Tohoku University, Sendai,
}

Japan

\section{Introduction}

Thermal spray coatings are deposited in an ambient atmosphere or vacuum chamber. Although vacuum plasma spray (VPS) coating is deposited inside vacuum, oxygen can penetrate into the flame during spraying process, as in high velocity oxygen-fuel (HVOF) spraying (C.J. Li \& W.Y. Li, 2003). This causes the spray materials to be exposed directly to an oxidizing atmosphere. This oxidation significantly influences the phase composition, microstructure, properties and performance of the sprayed coatings. Metal oxides are grown on the lamellar interface. The oxides are brittle and have different thermal expansion coefficients than that of the metal, the inclusion of which may cause the spalling of the coating (Neiser et al., 1998). Moreover, the inclusion of oxides in the MCrAlYs (where M is the alloy base metal; typically nickel, cobalt, or combination of these two), the coatings will degrade the resistance to sulfur and vanadium, etc., under high temperature corrosion. The presence of the oxides in steel coating also affects its mechanical properties (Volenik et al., 1997). However, some coating properties can be improved by metal oxides in sprayed coatings. A typical example is the improvment of wear resistance (Neiser et al., 1998). The deposited oxides increase also the hardness of the coating (Dobler et al., 2000). Therefore, it is important to understand the oxidizing behavior of spray materials at spraying.

The oxide content in the as-sprayed coating depends on the spraying technique, spraying parameters and starting material compositions (Dobler et al., 2000). Espie et al. reported that the oxygen content in plasma sprayed low carbon steel particles increased with spray distance (Espie et al., 2001). Fukushima and Kuroda presented similar effect for plasma sprayed Ni-20Cr coating, but they also reported that the oxygen content in the thermal sprayed coating was decreased with decreasing the stand-off distance (Fukushima and Kuroda, 2001). From the results in the study, it can be found that the oxygen content reached up to $10 \mathrm{wt}$. \% in plasma sprayed coatings, and others reported an oxygen intake up to 3-6 wt.\% in the coating deposited by HVOF process. The detailed examination in these studies revealed that there exists a clear difference in the grain size of powders. Therefore, it can be considered that such a difference in grain size of spray powder may be a cause responsible for the notable difference in coating oxygen content and oxidation behavior. From such a result, it may be considered that the properties of VPS process also might be affected by 
particle size, even though a vacuum process can better suppress oxidation of metallic coatings during spraying than the air plasma spray (APS) or HVOF process can.

The oxidation of metals depends on the rates at which anion or cation transport can occur through the crystal lattice or along grain boundaries in the oxide (Pomeroy, 2005). In alloys, which oxide is the most stable depends on the oxide dissociation pressure which is lowest for $\mathrm{Al}$ and $\mathrm{Cr}$ compared to the typical base elements $\mathrm{Fe}, \mathrm{Co}$ and $\mathrm{Ni}$. For $\mathrm{Ni}-\mathrm{Cr}$ alloys containing more than about 10 at. \% Cr, a continuous protective chromia layer is formed. A higher $\mathrm{Cr}$ level (25 at.\%) is required for Co-based alloys because $\mathrm{Cr}$ diffuses more slowly in Co and so cannot form a continuous chromia layer at lower concentrations (Pomeroy, 2005). Chromium oxide can itself oxidize at temperatures greater than about $1123 \mathrm{~K}$ to a volatile $\mathrm{CrO}_{3}$ compound. Because of this, the use of aluminium additions for oxidation resistance is preferred at this temperature and above for key components such as those used in gas turbines. There is added advantage, because the rate of formation of aluminium oxide is slower than for chromium oxide at the same temperature. Addition levels of $\mathrm{Al}$ to $\mathrm{Ni}$ for the formation of a continuous alumina scale are as for chromia formation (10 at.\%). Alumina formation at lower $\mathrm{Al}$ contents can be induced by mixed $\mathrm{Cr}+\mathrm{Al}$ additions since $\mathrm{Cr}$ getters oxygen allowing alumina to form at lower aluminium activities (contents) (Pomeroy, 2005). The aluminium and chromium contents referred to above apply to isothermal oxidation conditions. However, when thermal cycling conditions prevail, oxide scales can spall from the substrate surface due to thermally induced stresses.

Therefore, in this work, the influence of particle size and exposure time on the mechanical and oxidation behavior of selected VPS coatings was investigated. The particle and coating morphology, the oxygen contents of coatings, porosity, surface roughness, the growth rate of thermally grown oxide (TGO) thickness and mass gain, and the oxidation behavior were examined.

\section{Materials and experimental procedures}

Five commercially available CoNi- and CoCrAlY powders of different size ranges, from several micrometers to over $45 \mu \mathrm{m}$, were used as starting materials. Table 1 shows the nominal compositions of the five starting powders and the respective as-sprayed coating thickness, referred as (a) AMDRY-9951, (b) CO-210-1, (c) UCT-195, (d) CO-110, and (e) UCT1348. All powders were manufactured through gas atomization process. In order to obtain a reliable relationship between particle size and oxygen content, the particle size of the powders was measured statistically from scanning electron microscopy (SEM, Hitachi S4700, Japan) images. The Inconel 718 alloy (MA718, Mitsubishi Materials Co., Japan) was used as substrate to deposit the coating, which is widely used for gas turbine components. The chemical composition of the substrate material was $19 \mathrm{Cr}-19 \mathrm{Fe}-5.1 \mathrm{Nb}-3 \mathrm{Mo}-0.9 \mathrm{Ti}-0.5 \mathrm{Al}-$ balance Ni. The VPS processes were carried out with the A-2000V VPS system (Plasma Technik, Germany), under the following conditions: preheating temperature is $843 \mathrm{~K}$ during transferred arc treatment, voltage 56-57 V, current 580-590 A, spraying distance $310 \mathrm{~mm}$, argon gas atmosphere $8 \mathrm{kPa}$. The single face of substrate, which was $80 \times 70 \times 5 \mathrm{~mm}$ after pretreatment of blasting, was sprayed with $0.28 \mathrm{~mm}$ in average thickness.

To characterize the oxidation behavior, static oxidation experiments were carried out in air under isothermal condition at $1273 \mathrm{~K}$ up to $1000 \mathrm{~h}$. After eight-different exposure times, the 
specimens were characterized microstructurally using light optical and scanning electron microscopy (SEM; Hitachi S-4700, Japan). Each exposure condition consisted of high heating rate (about $32 \mathrm{~K} / \mathrm{min}$ ) in a kanthal muffle furnace, and about $3 \mathrm{~K} / \mathrm{min}$ cool-down to ambient temperature. The specimens were kept in alumina boats and then the boats were inserted into the furnace. The aim of this oxidation procedure was to create accelerated conditions for testing. The studies were performed on uncoated as well as plasma sprayed specimens for the purpose of comparison. Weight change measurements were made at the end of each exposure period with the help of an electronic balance (Sartorius LA120S, Germany) with a sensitivity of $0.1 \mathrm{mg}$. The coatings were removed from substrates and polished by $0.5 \mu \mathrm{m}$ alumina media before the weight gain measurements, to exclude the effect of surface roughness on the oxidation. The spalled scale also was included at the time of measurements of weight change to determine total rate of oxidation. The coated samples were degreased using ethanol and then subjected to optical microscopy, SEM and energy dispersive X-ray analysis (EDX; Oxford 6841, USA) to characterize the surface morphology. Electron spectroscopy for chemical analysis (ESCA; PHI Quantum 2000, USA) was also used to obtain surface profiles information in the first few layers, especially oxygen concentration profile. The porosity measurements were made with an image analyzer software (ImageJ, NIMH, USA), which is based on ASTM B276. The image was obtained through the SEM. After preliminary characterization, the samples were cross-sectioned, mounted in a conductive, phenolic resin with carbon filler and subjected to mirror polishing to identify the cross-sectional details. The coating thickness was measured by taking a back scattered electron image (BSEI) with the SEM, which was attached to a Robinson back scattered detector (RBSD). The surface roughness of the coatings was measured by the contactless measuring system (Mitaka NH-3T, Japan).

\begin{tabular}{|c|c|c|c|c|}
\hline \multirow[t]{2}{*}{ Type } & \multirow[t]{2}{*}{ Designation } & \multicolumn{2}{|c|}{ Chemical composition* (wt.\%) } & \multirow{2}{*}{$\begin{array}{l}\text { Coat thick. } \\
(\mu \mathrm{m})\end{array}$} \\
\hline & & Main & Trace & \\
\hline \multirow{3}{*}{ CoNiCrAlY } & (a) AMDRY-9951 & $\begin{array}{l}\text { 32Ni-21Cr-8Al-0.5Y- } \\
\text { Bal.Co }\end{array}$ & - & 269.15 \\
\hline & (b) $\mathrm{CO}-210-1$ & $\begin{array}{l}32 \mathrm{Ni}-21 \mathrm{Cr}-8 \mathrm{Al}-0.5 \mathrm{Y}- \\
\text { Bal.Co }\end{array}$ & $\begin{array}{l}\mathrm{Fe}, \mathrm{O}, \mathrm{C}, \mathrm{P}, \mathrm{Se}, \mathrm{N}, \mathrm{H}, \\
\mathrm{S}\end{array}$ & 247.85 \\
\hline & (c) UCT-195 & $\begin{array}{l}\text { 33Ni-21Cr-8Al-0.4Y- } \\
\text { Bal.Co }\end{array}$ & $\mathrm{Si}, \mathrm{Fe}, \mathrm{C}, \mathrm{P}, \mathrm{S}, \mathrm{O}, \mathrm{N}, \mathrm{H}$ & 308.54 \\
\hline \multirow{2}{*}{ CoCrAlY } & (d) $\mathrm{CO}-110$ & 23Cr-13Al-0.7Y-Bal.Co & $\mathrm{P}, \mathrm{C}, \mathrm{S}$ & 266.23 \\
\hline & (e) UCT-1348 & 23Cr-13Al-0.6Y-Bal.Co & $\mathrm{C}, \mathrm{H}, \mathrm{S}, \mathrm{P}$ & 316.38 \\
\hline
\end{tabular}

Table 1. Nominal compositions and coating thickness of the as-sprayed coatings

\section{Results and discussion}

\subsection{Morphology and oxygen contents in deposits}

Fig. 1 shows the typical morphology of spray powders screened into different sizes. It can be found that all powders have a spherical shape. The measurement of particle size using SEM images yielded the results shown in Table 2 and Fig. 2. From the results, it is clear that the measured mean particle size was larger than the mean value of the opening sizes of the 
sieves specified by suppliers. The AMDRY-9951 and CO-110 powders show the smallest and narrowest ranges than others.
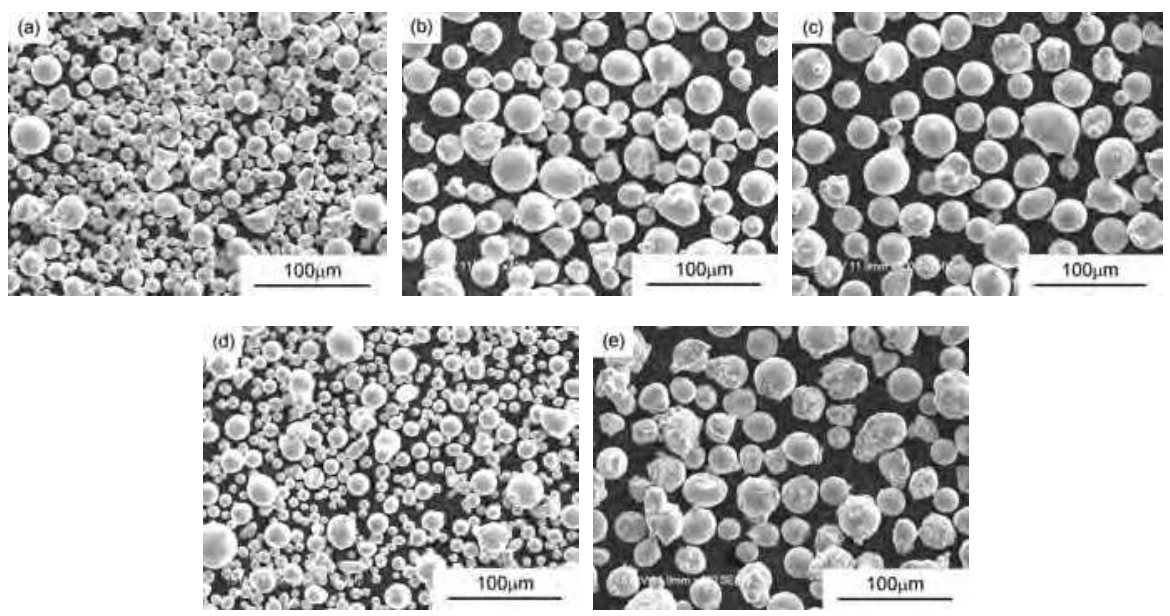

Fig. 1. Morphology of the spray powders: (a) AMDRY-9951; (b) CO-210-1; (c) UCT-195; (d) CO-110; (e) UCT-1348

\begin{tabular}{|c|c|c|c|c|c|c|c|c|}
\hline Designation & $\begin{array}{l}\text { Sieved } \\
\text { size }\end{array}$ & $\begin{array}{l}\text { Analyzed } \\
\text { size }\end{array}$ & Range & Mean & Median & S.D. & Variance & Error \\
\hline (a) AMDRY-9951 & $-35+5$ & $-34.5+2.5$ & 32.06 & 9.40 & 8.375 & 4.22 & 17.80 & 0.16 \\
\hline (b) CO-210-1 & $-45+10$ & $-43.5+3.6$ & 39.86 & 20.51 & 20.35 & 8.36 & 69.95 & 0.75 \\
\hline (c) UCT-195 & $-45+22$ & $-40.3+6.2$ & 34.1 & 24.84 & 26.34 & 7.59 & 57.55 & 0.84 \\
\hline (d) CO-110 & $-44+5$ & $-38.4+2.0$ & 36.39 & 10.08 & 8.58 & 4.79 & 22.99 & 0.22 \\
\hline (e) UCT-1348 & $-45+15$ & $-44.7+12.6$ & 32.06 & 25.71 & 25.04 & 6.51 & 42.33 & 0.72 \\
\hline
\end{tabular}

Table 2. Particle size ranges and descriptive statistics of powders $(\mu \mathrm{m})$

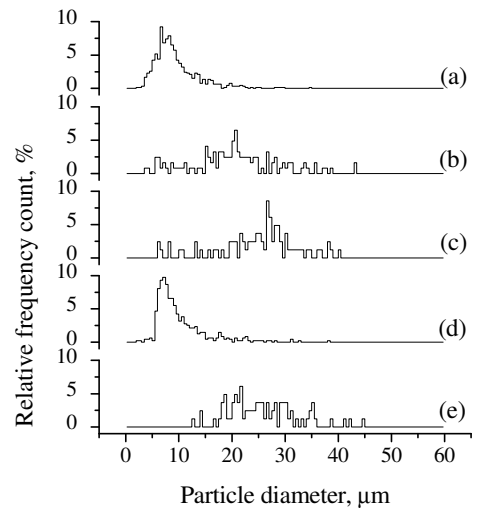

Fig. 2. Particle size distributions of the spray powders: (a) AMDRY-9951; (b) CO-210-1; (c) UCT-195; (d) CO-110; (e) UCT-1348 
Fig. 3 shows a cross-section of a collected particle of approximately $18 \mu \mathrm{m}$ in diameter and EDX analysis results obtained at three typical points marked as 1,2 and 3. It was found that there was a thin-splat-shell covering over the particle. The analysis revealed that this covering had oxide film formed during in-flight (point 3, Fig. 3a). Moreover, no evidence of oxygen was found inside the particle as shown in the point 1 of Fig. 3b. This result suggested that there is an interface between the oxide surface covering and the non-oxidized inner fraction of the particle. Therefore, in spite of VPS, the oxidation of an in-flight particle proceeds from particle surface towards the inside. As the result of referred research, Li et al. (C.J. Li \& W.Y. Li, 2003) showed an in-flight particle of HVOF spraying and its EDX analysis. The results of their analysis revealed that the thin-film-shaped covering was an oxide film formed during in-flight. During particle flight, with the decrease in the particle size, the oxygen content in the powders increase. When the mean particle size of powders was reduced to approximately $30 \mu \mathrm{m}$, the rapid increase in oxygen content in the in-flight powders was reported (C.J. Li \& W.Y. Li, 2003). It is clear that the particle size has a significant effect on the oxidization of the in-flight particle and consequently the oxygen content in spraying powders.

Generally, the oxidation of an alloy particle in a flame occurs on the particle surface. The oxygen content in the particle will increase with time because of the diffusion of oxygen from the surface towards the inside of the particle. Based on the relation between the oxygen content in an in-flight particle and the distance as reported by Espie et al. for plasma spraying, it can be considered that the oxygen content in the particle would follow the parabolic growth law, although the effect of internal flow in a well melted particle may occur and intensify the oxidation by exposing the fresh metal surface to the flame as pointed out by Neiser et al. and Espie et al. (Neiser et al., 1998; Espie et al., 2001). Therefore, at the initial stage, the oxygen content will be increased rapidly. With the progressing of the oxidation process, the increase in oxygen content will become less intensive. Moreover, after the particle flies off the high temperature zone of the flame, oxidation becomes slower. Due to the high stiffness of the flame, it was difficult to collect the powders at short spray distance. However, the very similar oxygen contents in both the coatings and in-flight particles provided evidence that the oxidation takes place mainly in the flame.
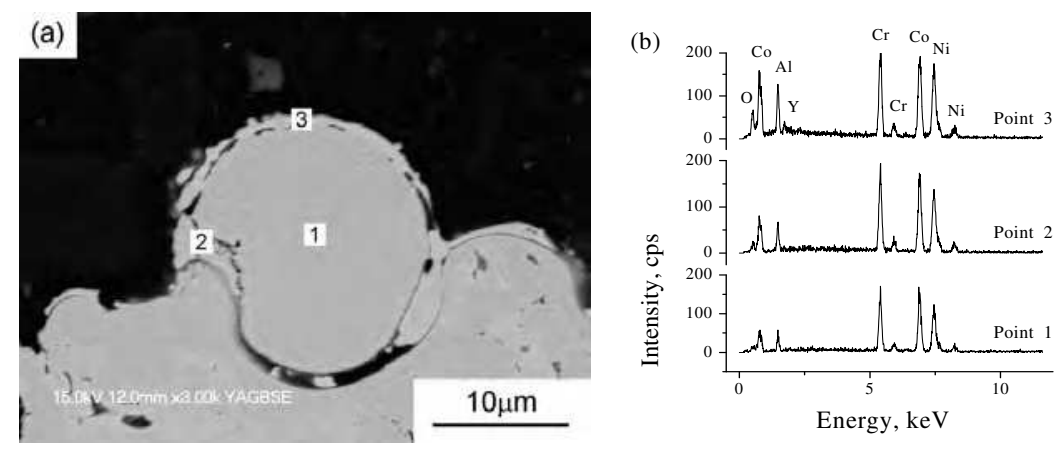

Fig. 3. Cross-sectional microstructure of a deposited particle using (a) CO-210-1 powder and (b) EDX spectrum analysis results at the center (point 1), near periphery (point 2) of unmelted particle, and fully melted splat (point 3) 
Fig. 4 shows the oxygen contents in the coatings versus mean particle size of the spray powder. It can be found that the oxygen contents in (a) AMDRY-9951 and (d) CO-110 coatings were larger than those in the other coatings. Table 3 shows the results of the oxygen contents in three kinds of starting powders and deposited coatings. It can be clearly observed that a remarkable increase in the oxygen content in the coating occurred with a decrease in the mean particle size. When the mean particle size is approximately $10 \mu \mathrm{m}$, the oxygen content was increased by a half order of magnitude with regard to the coating deposited by the powders larger than $20 \mu \mathrm{m}$. This implies that the decrease of mean powder size to a half will result in an increase in oxygen content by a half order of magnitude. It is clear that the particle size of spray powder has a substantial effect on the oxygen content in the deposited coating. This fact explains why the coatings deposited by the same type of material may significantly differ in the oxygen contents. Therefore, when the spray materials with grain size of less than $40 \mu \mathrm{m}$ are used and the oxidation is involved, the particle size and the distribution of the size as well should be taken into account essentially.

But after thermal exposure, the difference of the oxygen contents between the smaller and larger particle coatings was decreased with increasing exposure time. Generally, the oxide scale growth in isothermal condition initiates on the free surface of coatings. The oxygen content in the exposed coating will increase with exposure time because of the diffusion of oxygen from the surface towards the inside of the coating. Therefore, at the initial stage (1 hour), the oxygen content was increased rapidly. With the progressing of the oxidation process, the increase in oxygen content will become less intensive. So the influence of particle size on the oxygen content in the aged coating also becomes less intensive as shown in Fig. 4 and Table 3. The oxides in the as-sprayed coatings result from powder oxidation.

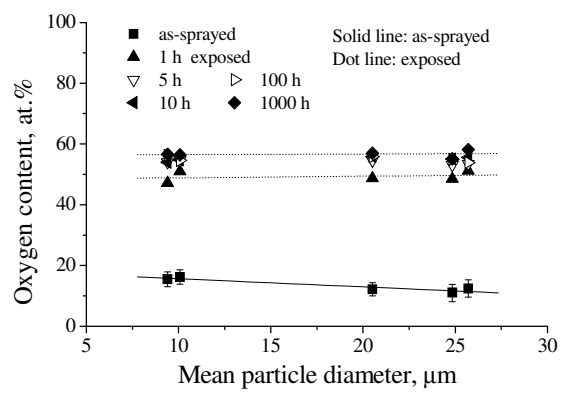

Fig. 4. Effect of particle size on the oxygen content in CoNi-/CoCrAlY coatings

\begin{tabular}{|c|c|c|c|c|c|c|c|c|}
\hline \multirow[t]{3}{*}{ Designation } & \multirow{3}{*}{$\begin{array}{l}\text { Powder* } \\
\text { (wt. \%) }\end{array}$} & \multicolumn{7}{|c|}{ Coating (at. \%) } \\
\hline & & \multicolumn{6}{|c|}{ In micro-level depth** } & \multirow{2}{*}{$\begin{array}{l}\begin{array}{l}\text { Nano- } \\
\text { level }\end{array} \\
\text { As-sprayed }\end{array}$} \\
\hline & & As-sprayed & $1 \mathrm{~h}$ & $5 \mathrm{~h}$ & $10 \mathrm{~h}$ & $100 \mathrm{~h}$ & $1000 \mathrm{~h}$ & \\
\hline AMDRY-9951 & - & 15.50 & 47.13 & 54.05 & 54.04 & 56.22 & 56.60 & 58.55 \\
\hline CO-210-1 & 0.028 & 12.18 & 48.70 & 54.58 & 55.89 & 55.90 & 56.97 & 59.93 \\
\hline UCT-195 & 0.040 & 11.12 & 48.52 & 53.16 & 55.04 & 54.86 & 55.16 & 59.14 \\
\hline
\end{tabular}

* Specified by supplier. ${ }^{* *}$ Measured using EDX. ${ }^{* * *}$ Measured using ESCA.

Table 3. Oxygen contents in starting powders and coatings 


\subsection{Effect of particle distribution on the porosity of coatings}

Fig. 5 shows the distribution of the cross-sectional porosity in the coating about $100 \mu \mathrm{m}$ from the coating surface versus particle size. The amount of porosity increased normally with increasing particle size. This, of course, could be due to reduced melting efficiency of the coarser particles in the plasma plume. The coating from the finer powder shows welladhered splats, while the interlamellar pores are more prominent in the medium powder coating. The unmelted and poorly adhered particles can be seen in the coarse powder coating. Earlier studies (Kulkarni et al., 2003) have shown that the morphology of the splats changes from a contiguous disk-like shape to a fragmented shape with increasing particle size. These fragmented splats lead to poor splat-splat contact and to the formation of pores. But the distribution of particle size plays the important role of porosity than only the particle size. In some cases the unmelted particles press the splats and make the poorly bonded splat-splat contact closed as shown in Fig. 6. The (b) CO-210-1 coating shows the lowest porosity, this could be due to the good compacting of the small, medium and larger particles. This powder has the widest range and sample variance as shown in Table 2, so these lead to low porosity inside the coating during the deposition process.
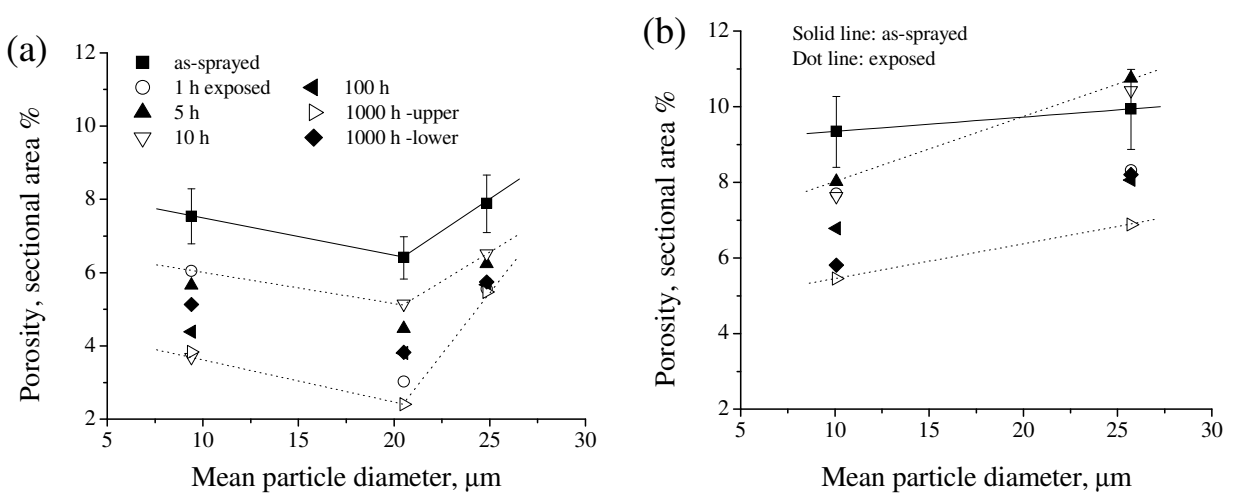

Fig. 5. Effect of particle size on the porosity of (a) CoNiCrAlY and (b) CoCrAlY coatings

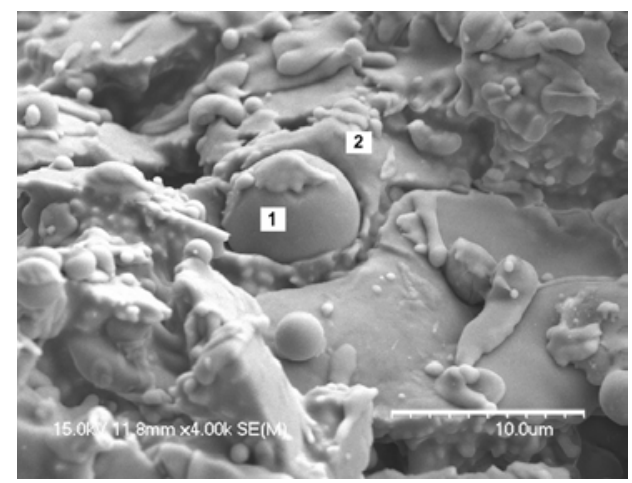

Fig. 6. Compressing phenomenon of the as-sprayed CoNiCrAlY (UCT-195) coatings: (1) an unmelted particle; (2) the pressed splat by the particle 
As shown in Fig. 5, with increasing exposure time, the amount of porosity decreased gradually in all coatings. Upon detail review of the CoNiCrAlY coatings, the porosity decreased at Stage I (1-10 h of (a) AMDRY-9951, and 0-1 h of (b) CO-210-1 and (c) UCT-195), and increased at Stage II (10-100 h of (a) AMDRY-9951, and 1-10 h of (b) CO-210-1 and (c) UCT-195), and then finally decreased again beyond Stage II. Stage I represents the sintering effect. These sharp changes in porosity after short sintering times have also been observed by Thompson and Clyne (Thompson \& Clyne, 2001). It might be expected that short exposure (Stage I) to temperatures is sufficient to heal cracks and lock splats together leading to decreased porosity inside of the MCrAlY coatings. Inside pores concentrated on the lower part of the coating over the Stage II.

From the cross-sectional morphology of the interfaces between the MCrAlY coatings and the substrates after 1000 hours of exposure, the intergranular voids present in the scale which may be formed. In the absence of the effective shrinkage for vacancies, vacancies generated by outward diffusion of alloying elements such as $\mathrm{Ni}$ or Co condense to form cavities. One of the most effective methods to develop oxidation resistance in alloys and coatings at temperatures above about $1223 \mathrm{~K}$ is to form continuous scales of $\mathrm{a}-\mathrm{Al}_{2} \mathrm{O}_{3}$ via selective oxidation. As the oxidation time increase, transient oxidation stage is represented by the formation of the protective alumina oxide layer, followed by Al-depletion, $\mathrm{Ni}$ or $\mathrm{Co}$ outward diffusion and solid state reaction with pre-existing alumina to form spinel phase, and the $\mathrm{Cr}_{2} \mathrm{O}_{3}$ formation at the oxide-to-metal interface. These processes highly depend on the oxidation temperature and microstructures of the VPS MCrAlY coatings.

Authors tried to predict the porosity of as-sprayed coatings, using bi- or tri-models which are composed with two or three type of particle diameters as shown in Table 4. But, real porosity values are lower than proposed theoretical values. It is believed that most particles are round and spherical, but small particles change to flat shape. Generally, packing of spheres leads to a higher density than other shapes. To predict more exactly, splat-reflected model is required, and more useful. The apparent density of the metal powder is influenced by many factors, such as particle size, shape, size distribution, inter-particle friction, surface chemistry, agglomeration and packing type, etc. In general, with the decrease of the particle size, the packing density decreases because of the higher inter particle friction. The greater the surface roughness or the more irregular the particle shape, the lower the packing density is. A higher relative apparent density can be achieved by mixing different sizes of powders. The principle involves using finer particles to fill the voids formed by the larger powders.

Fig. 7 shows four possible occurrences in the mixture with different sizes of powders, where L, M and S represent the diameters of the large, middle and small spheres, respectively. From these models, it can be found that using the tri-modal arrangement one can obtain the highest apparent density (Fig. $7 \mathrm{~b}$ ), and using bi-modal, i.e. mono-sized small particles with one middle-sized particle yields the lowest apparent density (Fig. 7a). The quantitative analysis has been conducted as shown in Table 4. For instance, an ideal situation is shown for plain tri-modal particles in Fig. $7 \mathrm{~b}$ where the small size disk just touches the large neighboring disks. In fact, the composition of a mixture according to the geometrical relationship is not feasible. This is caused by two reasons. The first reason is that metal powders consisting of purely mono-sized particles are impossible to attain. In spraying process, the powder mixture always consists of several powders. Another is that the size of the powder in spraying is restricted by many factors, such as layer thickness, flowability, deposit characteristic and cost. 


\begin{tabular}{lllllll}
\hline Designation & $\begin{array}{l}\text { Dia. } \\
\text { group }\end{array}$ & $\begin{array}{l}\text { Frequency } \\
\text { count ratio }\end{array}$ & $\begin{array}{l}\text { Mean dia. } \\
\text { ratio }\end{array}$ & $\begin{array}{l}\text { Mean dia. } \\
(\mu \mathrm{m})\end{array}$ & $\begin{array}{l}\text { Porosity (area \%) } \\
\text { Theoretical }\end{array}$ & $\begin{array}{l}\text { Measured } \\
\text { (a) AMDRY-9951 }\end{array}$ \\
& $\mathrm{S}$ & 14.69 & 1.00 & 8.60 & 22.92 & 6.87 \\
(b) CO-210-1 & $\mathrm{M}$ & 1.00 & 2.38 & 20.50 & & \\
& $\mathrm{~S}$ & 2.43 & 1.00 & 10.64 & 14.42 & 4.96 \\
& $\mathrm{M}$ & 5.36 & 2.08 & 22.15 & & \\
(c) UCT-195 & $\mathrm{L}$ & 1.00 & 3.36 & 35.71 & & \\
& $\mathrm{~S}$ & 0.79 & 1.00 & 10.30 & 28.73 & 6.19 \\
& $\mathrm{M}$ & 4.07 & 2.44 & 25.14 & & \\
\hline (d) CO-110 & $\mathrm{L}$ & 1.00 & 3.40 & 35.02 & & \\
& $\mathrm{~S}$ & 1.00 & 1.00 & 5.62 & 30.44 & 7.47 \\
(e) UCT-1348 & $\mathrm{M}$ & 7.36 & 1.86 & 10.46 & & \\
& $\mathrm{M}$ & 4.27 & 1.00 & 23.85 & 29.93 & 7.91 \\
& $\mathrm{~L}$ & 1.00 & 1.51 & 36.03 & & \\
\hline
\end{tabular}

* $\mathrm{S}, \mathrm{M}$ and $\mathrm{L}$ represent the groups of the small, middle and large particles. Range of $\mathrm{S}, \mathrm{M}$ and $\mathrm{L}$ are $16.3+2.0,-30.6+16.3$, and $-45.0+30.6$, respectively.

Table 4 . Theoretical analysis of porosity and particle distribution of as-sprayed coatings

(a)

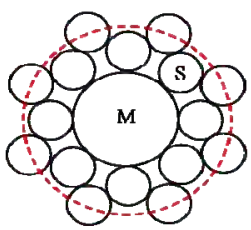

(c)

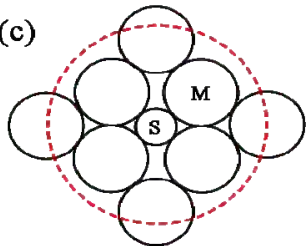

(b)

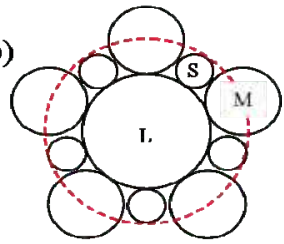

(d)

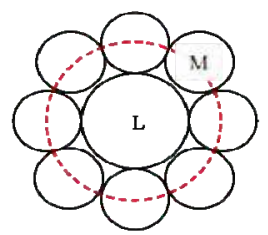

Fig. 7. Plain bi- and tri-model of powder deposition for: (a) AMDRY-9951; (b) CO-210-1 and UCT-195; (c) CO-110; (d) UCT-1348

\subsection{Effect of exposure time on the porosity of coatings}

Fig. 8 shows the distribution of the cross-sectional porosity in the coating about $100 \mu \mathrm{m}$ depth from the free surface of coatings according to the increase of exposure time. The amount of porosity increased normally with increasing the particle size. This, of course, could be due to reduced melting efficiency of coarser particles in the plasma plume. A coating from fine powder shows well-adhered splats, while the interlamellar pores are more prominent in medium powder coating. The unmelted and poorly adhered particles can be seen in the coarse powder coating. Earlier studies (Kulkarni et al., 2003) have shown that the morphology of the splats changes from a contiguous disk-like shape to a fragmented shape with increasing particle size. These fragmented splats lead to poor splat-splat contact and to 
the formation of pores. But the distribution of particle size performs the important role of porosity than only the particle size. Some cases the unmelted particles press the splats and make the poor splat-splat contact close. The CO-210-1 coating shows the lowest porosity, this could be due to the good compounding the small, medium and larger particles. This powder has the widest range and sample variance as shown in Table 2, so these lead to make lower porosity inside coatings during the deposition process.

As shown in Fig. 8, with increasing exposure time, the amount of porosity decreased gradually in all coatings. But in view of details, the porosity decreased at Stage $\mathrm{I}_{\mathrm{P}}(0-10 \mathrm{~h}$ for AMDRY-9951 coating; 0-1 h for CO-210-1 and UCT-195 coatings), and increased at Stage IIP (10-100 $\mathrm{h}$ for AMDRY-9951 coating; 1-10 h for CO-210-1 and UCT-195 coatings), and then finally decreased again over Stage $I_{P}$. Stage $I_{P}$ represents the sintering effect as shown in Fig. 9. These sharp changes in porosity after short sintering times have also been observed (Thompson \& Clyne, 2001). It might be expected that short exposure (Stage $\mathrm{I}_{\mathrm{P}}$ ) to high temperatures sufficient to heal cracks and lock splats together would lead to decrease the porosity inside of CoNiCrAlY coatings. Internal pores concentrated on the lower part of coating (over $100 \mu \mathrm{m}$ from coating surface) over the Stage $\mathrm{II}_{\mathrm{P}}$ as shown in Fig. 10. From the cross-sectional morphology of the interfaces between CoNiCrAlY coatings and substrates after $1000 \mathrm{~h}$ exposure, the intergranular voids present in the scale which may be formed, as described by Choi (Choi et al., 2002). In the absence of the effective sinks for vacancies, vacancies generated by outward diffusion of alloying elements such as $\mathrm{Ni}$ or Co condense to form cavities. One of the most effective methods to develop oxidation resistance in alloys and coatings at temperatures above about $1223 \mathrm{~K}$ is to form continuous scales of $\mathrm{a}-\mathrm{Al}_{2} \mathrm{O}_{3}$ via selective oxidation. As the oxidation time increase, transient oxidation stage is represented, and then protective alumina oxide layer formation, Al-depletion, $\mathrm{Ni}$ or $\mathrm{Co}$ outward diffusion and solid state reaction with pre-existing alumina to form spinel phase, $\mathrm{Cr}_{2} \mathrm{O}_{3}$ formation at the oxide-to-metal interface, these processes highly depend on the oxidation temperature and microstructures of the MCrAlY coatings.

It reveals that the substrate interface possessed a lot of processing defects like pores (3.5-6\% porosity) in $1000 \mathrm{~h}$ heat exposed specimens. Further, it was evident that the metallic MCrAlY overlay coating also possessed a lot of porosities as defects incorporated from plasma spraying. An Al-depleted zone at the overlay coat/substrate interface as well as just below the TGO along the TGO/MCrAlY interface was observed in the heat exposed specimens. Similar observations were also made by previous investigators in studying the oxidation behavior of sprayed MCrAlY coatings in air (Brandl et al., 1996; Ray \& Steinbrech, 1999; Ray et al., 2001). They have observed Al depleted zone below the MCrAlY coating and also below the TGO scale after a long time oxidation of $500 \mathrm{~h}$. The MCrAlY coat/substrate interface revealed the presence of porosity and carbide precipitations (Ray \& Steinbrech, 1999; Ray et al., 2001) in heat exposed specimens. The metal matrix shows grain growth with carbide precipitation within the grains. Possibly secondary carbides precipitate out along the grain boundaries and primary carbides in the center of the grains as described in some references (Ray \& Steinbrech, 1999; Ray et al., 2001). Due to the high oxygen conductivity of scales at high temperature and the presence of porosity in the TGO and in the MCrAlY coating, the $\mathrm{Al}$ in the MCrAlY coat oxidizes to $\mathrm{Al}_{2} \mathrm{O}_{3}$ at the TGO/MCrAlY coat interface. Therefore following this interface, there is an $\mathrm{Al}$ depleted zone in the MCrAlY coat. It appears that a fraction of $\mathrm{Al}$ in the $\mathrm{MCrAlY}$ coating also diffuses into substrate. Therefore an Al depleted zone also occurs between the interface of the MCrAlY/substrate and the 
MCrAlY coat. Previous authors have also reported similar observations in such MCrAlY overlaid substrates (Brandl et al., 1996; Ray \& Steinbrech, 1999; Ray et al., 2001).

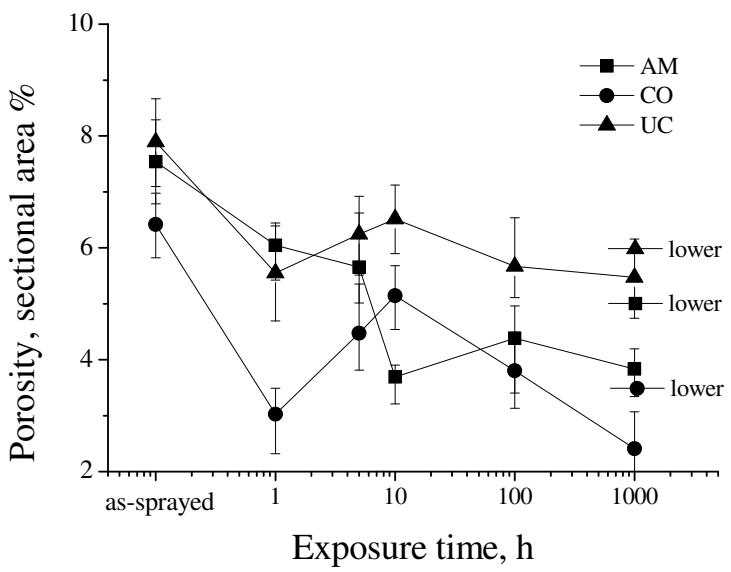

Fig. 8. Effect of exposure time on the porosity of CoNiCrAlY coatings with heat exposure

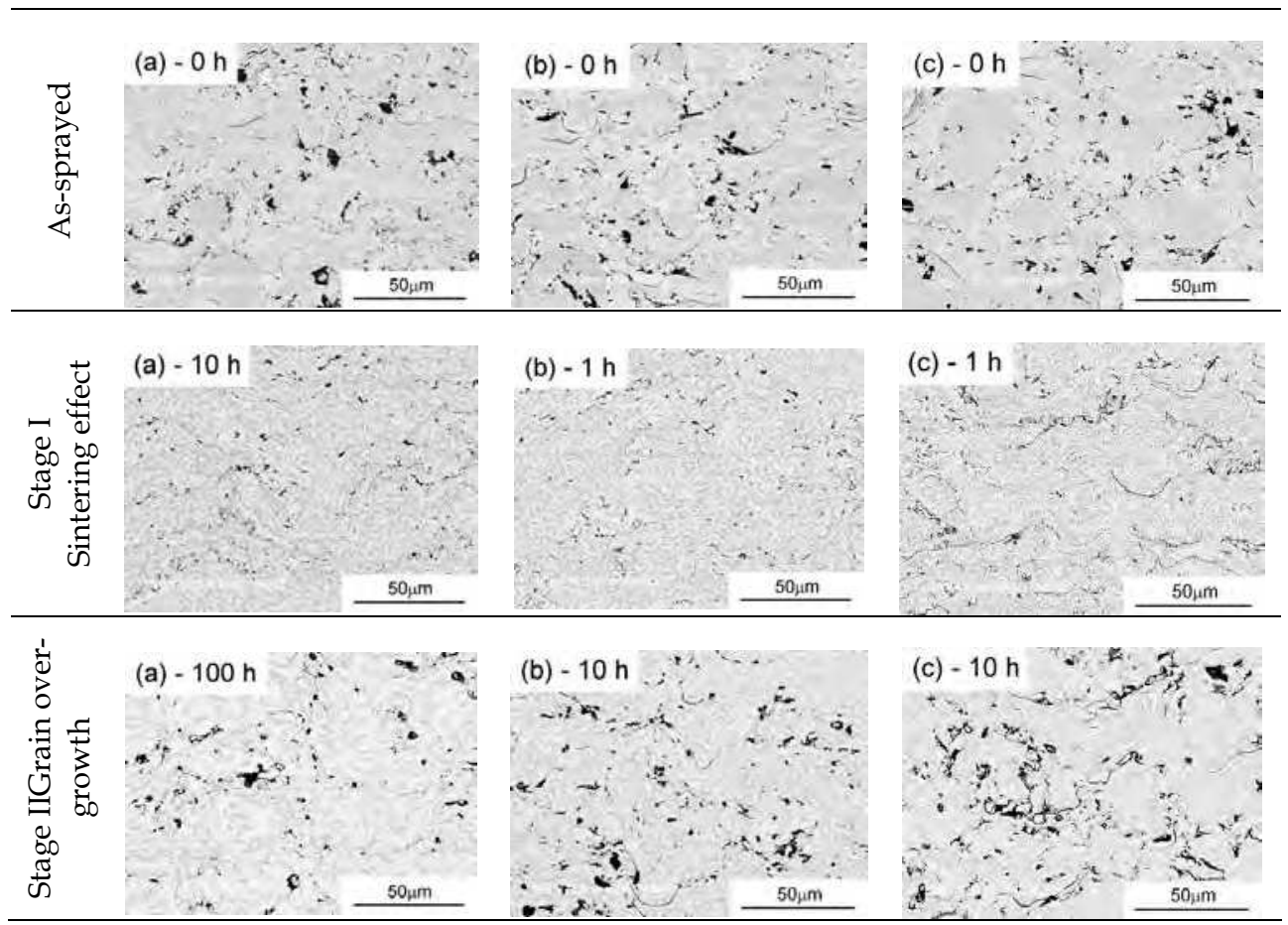

Fig. 9. Transformation of internal pore of (a) AMDRY-9951, (b) CO-210-1, and (c) UCT-195 coatings with various exposure time 


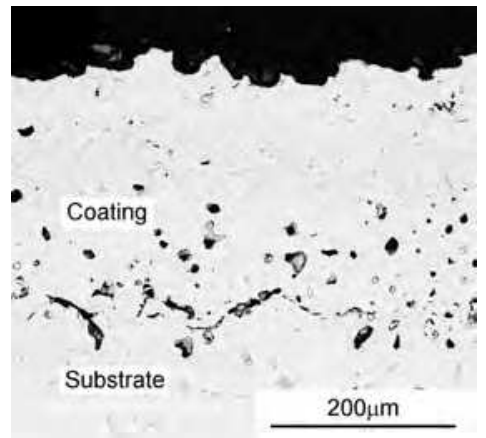

Fig. 10. Internal pore microstructure of the 1000 h-exposed CO-210-1 coating

\subsection{Effect of exposure time on the surface roughness and TGO}

Fig. 11 shows the surface roughness of as-sprayed and exposed coatings with increasing exposure time. The surface roughness increased with increasing the particle size all over. The surface roughness decreased up to Stage $I_{R}$ (0-1 h for AMDRY-9951 coating; 0-5 h for CO-210-1 and UCT-195 coatings) with increasing exposure time, but over the time of Stage $I_{R}$, surface roughness was kept in relatively fixed value or increased slightly. This could be due to the partial sintering effect of inter-splat pores at the time of Stage $\mathrm{I}_{R}$. And another possibility is due to the TGO, i.e., the growth of spinel-type $\mathrm{Al}_{2} \mathrm{O}_{3}$ on the surface as shown in Fig. 12(a). The open pores of surface could be filled with these oxides as shown in Fig. 13. Tang et al. (Tang et al., 2004) also showed that the oxide scale grown on the coating consisted primarily of spinel-type oxides after $1 \mathrm{~h}$ exposure at $1273 \mathrm{~K}$. After exposure at 1273 $\mathrm{K}$ for longer time, beside the spinel-type oxides, $\mathrm{a}$-alumina and $\mathrm{Cr}_{2} \mathrm{O}_{3}$ were also identified (will be discussed at section 3.5). The TGO scale was concentrated on the valley of surface from initial $1 \mathrm{~h}$ exposure to heat, as shown in Fig. 13 (point 1). At next stage, TGO scales also grew on the convex surface (hill-side), so the surface roughness increased slightly (refer to Fig. 11). And then the roughness decreased again or kept in relatively fixed value. The crystal size of grown scales is relatively small than the concavo-convex as-sprayed surfaces, so the heat-exposed surface becomes smooth and fine-grained gradually.

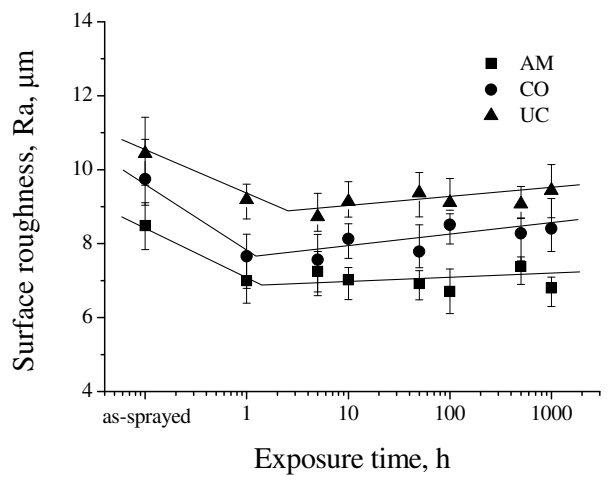

Fig. 11. Effect of exposure time on the surface roughness of CoNiCrAlY coatings 

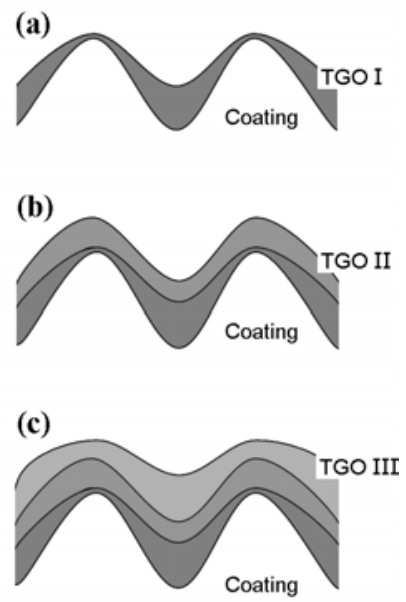

Fig. 12. Schematics of the surface roughness transition with TGO growth

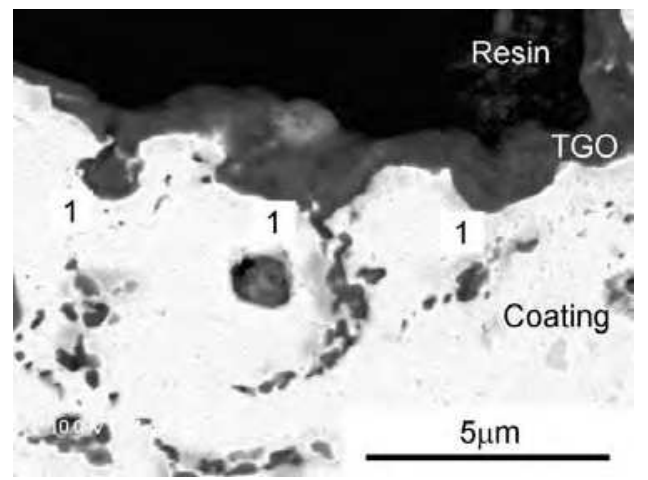

Fig. 13. Transition of surface roughness after heat exposure of 1 h (AMDRY-9951 coating); TGO scales are filled into the concave surfaces (point 1) at first step, and then grow on the convex surfaces

The TGO thickness and weight gain plots for the three coatings and substrate in static air at $1273 \mathrm{~K}$ are shown in Fig. 14(a) and (b) respectively. The square value of TGO thickness was proportional to the square root of exposure time, and the square value of weight gain was proportional to the heat exposure time. The oxidation can be divided into two stages (Choi et al., 2002). One is the transient oxidation stage which shows initial relatively rapid oxidation rate and the other is the steady-state oxidation stage which shows a relatively slow oxidation rate. The transition time from the initial transient oxidation to the steadystate oxidation can be defined as the time of intersection of the extrapolation lines of the initial rapid oxidation and that of the later slow oxidation. The transition times for all the coatings which show this transition were below $23 \mathrm{~h}$. UCT-195 coating showed a faster oxidation rate than other coatings at both plots, which might be due to the bigger particle size and higher surface roughness shown in Fig. 11. AMDRY-9951 coating shows the lowest rate of TGO thickness growth and weight gain, but UCT-195 coating shows the highest. 
(a)

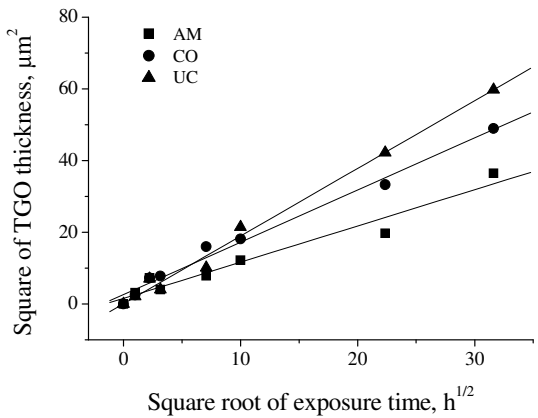

(b)

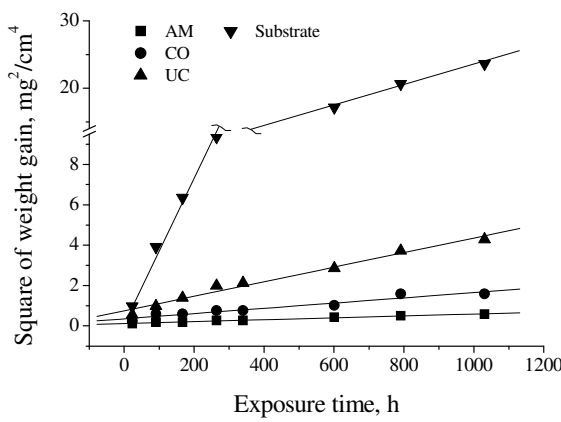

Fig. 14. Effect of exposure time on the (a) oxide scale thickness and (b) weight gain of heat exposed coatings

All the coatings exhibited a tendency to have uniform TGO thickness and weight gain after an initially higher rate of oxidation, i.e. they followed the parabolic rate law of oxidation. The parabolic oxidation rate constant is generally defined by the equation $(\Delta W / A)^{2}=k_{p} t$ where $\Delta \mathrm{W}$ is the weight change at any time, $\mathrm{A}$ is the surface area, $\mathrm{t}$ is time and $\mathrm{k}_{\mathrm{p}}$ is the constant for the parabolic rate law (Tang et al., 2004; Briks \& Meier, 1983). The parabolic rate constants are $4.65 \times 10^{-4}, 1.3 \times 10^{-3}$, and $3.6 \times 10^{-3} \mathrm{mg}^{2} \mathrm{~cm}^{-4} \mathrm{~h}^{-1}$ for AMDRY-9951, CO-210-1, and UCT-195 coatings, respectively. Thus, the rate constant of AMDRY-9951 coating is a factor of eight smaller than that of UCT-195 coating. The weight gain of AMDRY-9951 coating (0.5 $\mathrm{mg} / \mathrm{cm}^{2}$ ) also showed over sextuple lower value than that of uncoated substrate (3.4 $\mathrm{mg} / \mathrm{cm}^{2}$ ) at $340 \mathrm{~h}$. But substrate Inconel 718 does not follow an exact parabolic rate law, this may be because inhomogeneous oxides locally formed and grew rapidly below $340 \mathrm{~h}$ (Tang et al., 2004). The transient oxidation stage which shows a rapid oxidation rate can not be explained by Wagner's model (Briks \& Meier, 1983). From the gradients of the plots, approximate values for the parabolic rate constant, $\mathrm{k}_{\mathrm{p}}$, were calculated for the transient and steady-state oxidation range of Fig. 14b. These were $3.32 \times 10^{-2}$ and $1.74 \times 10^{-2} \mathrm{mg}^{2} \mathrm{~cm}^{-4} \mathrm{~h}^{-1}$ for the transient and steady-state range, respectively. Decrease of gradient occurs after oxidation time of $340 \mathrm{~h}$. These calculated $\mathrm{k}_{\mathrm{p}}$ values cannot be compared directly with the data of coatings owing to the differences in compositions. However, they are higher than the corresponding value for the coatings. In particular, in the case of steady-state oxidation range, the rate constant of UCT-195 coating is a factor of five smaller than that of substrate.

The rates of TGO thickness growth and weight gain increase with increasing the particle size of starting powder. The oxide scales of AMDRY-9951 coating exhibited excellent adhesion to the overlay coating relatively, although minor cracks were observed during the isothermal oxidation as shown in Fig. 15a. CoNiCrAlY coatings had two important and inherent discontinuities that could act as non-uniform oxide formation sites (Tang et al., 2004). One is the oxide stringers that result from an oxidation reaction between scaleforming elements ( $\mathrm{Al}$ or $\mathrm{Y}$ ) in a molten droplet and oxygen entrapped from the surrounding atmosphere. This phase implies pre-consumption of $\mathrm{Al}$, a very important scale-forming element while there is poor contact at the matrix and oxide stringer interface. The other is the improperly flattened zones that are due to the deposition of partially melted particles resulting from insufficient heat transport during flight and splashing of spreading particles impacting on rough surface. These zones have high densities of open pores that are easy 
penetration paths for oxygen, leading to internal oxidation. These two features have influenced the oxidation behavior in both the transient and steady-state oxidation stage. Owing to above reasons, AMDRY-9951 coating, which has the lowest surface roughness as shown in Fig. 11, presented the smaller TGO thickness growth rate and parabolic oxidation rate constant than other coatings.
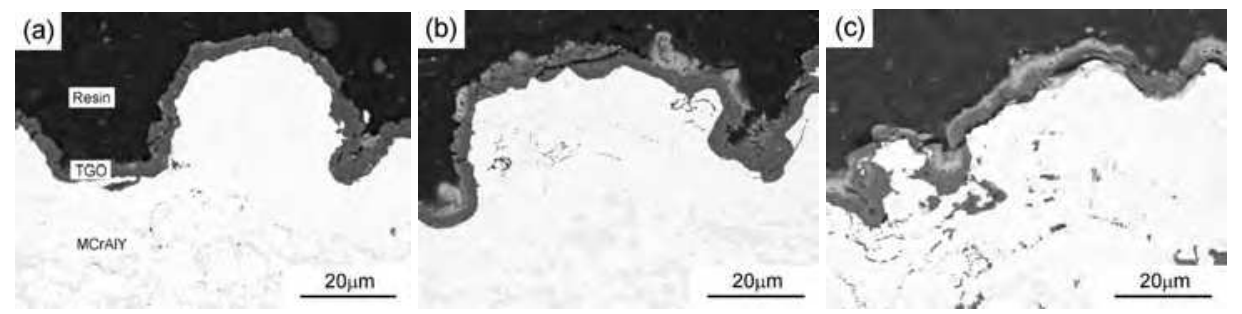

Fig. 15. Formation of the TGO on the surface of the CoNiCrAlY coatings after $100 \mathrm{~h}$ exposure: (a) AMDRY-9951; (b) CO-210-1; (c) UCT-195

\subsection{Effect of chemical composition on the oxidation of coatings}

Fig. 16 shows the results of EDX analysis of the CoNiCrAlY coatings according to the heat exposed time. There were metallic phases composed mainly of $\mathrm{Cr}, \mathrm{Co}$ and $\mathrm{Ni}$ for as-sprayed coatings. The absence of peaks corresponding to the oxide phases in the as-sprayed coatings is due to the relatively small thickness of the oxide scale, in spite of the presence of the oxide layer on the surface of the as-sprayed coatings. In the case of the exposed coatings at $1273 \mathrm{~K}$, all three coatings showed similar oxidation behaviors especially from the initial oxidation stages. The major metallic elements, i.e., $\mathrm{Cr}$, $\mathrm{Co}$ and $\mathrm{Ni}$ decreased, but $\mathrm{Al}$ and $\mathrm{O}$ increased gradually according to increasing the exposure time. This phenomenon represents the growth of $\mathrm{Al}_{2} \mathrm{O}_{3}$ oxides. But over $100 \mathrm{~h}$ exposure time for the CO-210-1 and UCT-195 coating, $\mathrm{Cr}$, Co and $\mathrm{Ni}$ elements have become much richer than $\mathrm{Al}$ relatively. These $\mathrm{Cr}-\mathrm{Co}-$ $\mathrm{Ni}-\mathrm{O}$ systems represent the development of typical mixed oxides at the latter thermal exposure stage. In the case of AMDRY-9951 coating, this phenomenon starts from $1000 \mathrm{~h}$, and the peaks of $\mathrm{Cr}$, Co and $\mathrm{Ni}$ were relatively lower than other coatings. It may be inferred from the above that AMDRY-9951 coating which has a relatively narrow range of particles has less mixed oxides left on the exposed surfaces than other coatings.

In order to understanding the development of corrosion protective coatings, it is necessary to appreciate the processes by which oxidation and corrosion occur and how the mechanisms by which they occur depends on environmental and temperature. Three accelerated degradative processes occur depending on temperature and these can be defined in order of increasing temperature as: Type II hot corrosion, Type I hot corrosion and oxidation (see Fig. 17) (Briks \& Meier, 1983). Type II hot corrosion occurs at temperatures in the range $600-800{ }^{\circ} \mathrm{C}$ and involves the formation of base metal (nickel or cobalt) sulphates which require a certain partial pressure of sulphur trioxide for their stabilization. These sulphates react with alkali metal sulphates to form low melting point compounds which prevent a protective oxide forming. Indeed, the oxide formed as a striated one has shown that $\mathrm{Ni}-\mathrm{Cr}-\mathrm{Al}$ materials resist this form of corrosion most effectively (Viswanathan, 2001; Nicholls et al., 2002). Type I hot corrosion involves the transport of 
sulphur from a sulphatic deposit (generally $\mathrm{Na}_{2} \mathrm{So}_{4}$ ) across a preformed oxide into the metallic material with the formation of the most stable sulphides. Once stable sulphides formers (e.g. Cr) are fully reacted with the sulphur moving across the scale, then base metal sulphides can form with catastrophic consequences as they are molten at the temperatures at which Type I hot corrosion is observed $\left(800-950^{\circ} \mathrm{C}\right)$ (Viswanathan, 2001; Eliaz et al., 2002). Thus, the formation of $\mathrm{NiS}_{2}$ (molten at $645^{\circ} \mathrm{C}$ ) and $\mathrm{Co}_{x} \mathrm{~S}_{\mathrm{y}}$ (lowest liquidus $\sim 840^{\circ} \mathrm{C}$ ) can cause degradation levels which are serious enough to cause major component degradation. The most suitable materials which can resist Type I hot corrosion are $\mathrm{PtAl}_{2}-(\mathrm{Ni}-\mathrm{Pt}-\mathrm{Al})$ coatings and M-CrAlY coatings containing up to 25 wt.\% Cr and 6 wt.\% Al (Goward, 1998). The oxidation resistance under such conditions can be markedly improved by the addition of socalled reactive elements $(\mathrm{Y}, \mathrm{Hf}, \mathrm{Ce})$ to alloys and coatings. An exhaustive search for the reasons behind this effect has finally shown that yttrium and rare earth metals segregate to grain boundaries within alumina scales causing a reduction in $\mathrm{Al}$ and $\mathrm{O}$ transport rates through the oxide and thus reduced oxidation rates (Pint, 1996). Furthermore, reactive elements combine with sulphur and phosphorus impurities in metallic materials and coatings with the result that these impurities cannot selectively diffuse to the surface and contaminate the oxide-metallic interface. This gives extremely good scale adherence and categorically explains why minor yttrium or cerium $(<0.8 \%)$ additions to oxidation resistant coatings and alloys greatly improve oxidation resistance.

(a)

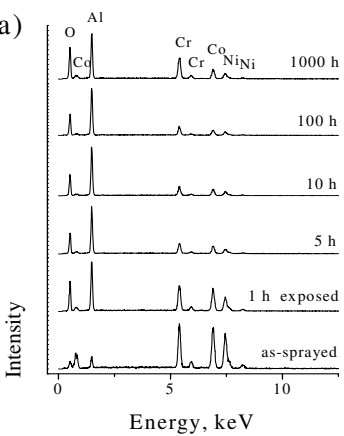

(b)

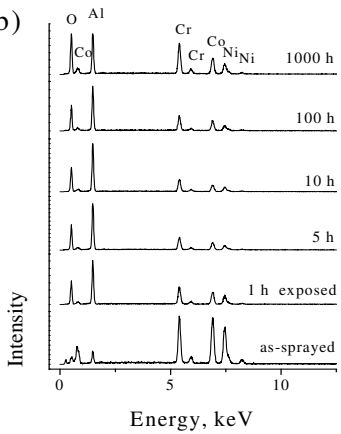

(c)

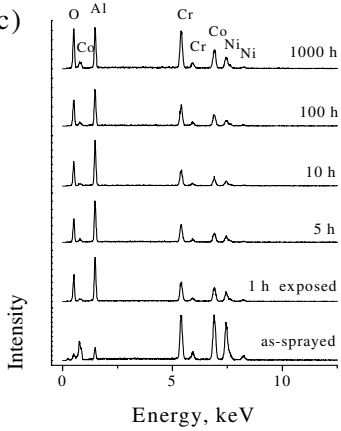

Fig. 16. EDX spectrum analysis results of (a) AMDRY-9951, (b) CO-210-1 and (c) UCT-195 coatings according to exposure time

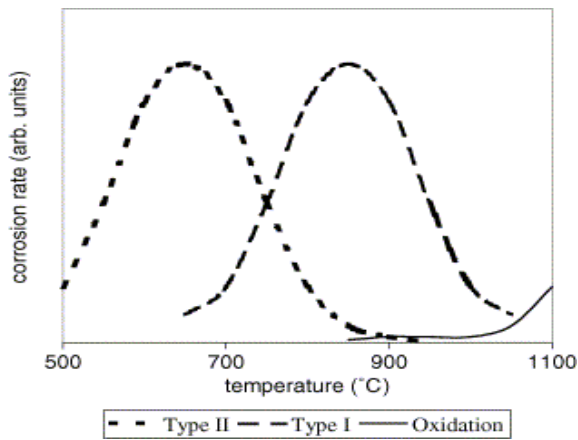

Fig. 17. Relative oxidation and corrosion resistance of high temperature coating systems. 
Hot corrosion problems (type I and type II hot corrosion, vanadic corrosion) are a direct result of salt contaminants such as $\mathrm{Na}_{2} \mathrm{SO}_{4}, \mathrm{NaCl}$ and $\mathrm{V}_{2} \mathrm{O}_{5}$ which, in combination, produce low melting point deposits which dissolve the protective surface oxides. A number of fluxing mechanisms has been proposed to account for the different corrosion morphologies that are observed (Briks \& Meier, 1983 ; Khanna, 2004) and this has resulted in the general classification of high temperature (type I) hot corrosion, low temperature (type II) hot corrosion and vanadic corrosion $\left(535-950^{\circ} \mathrm{C}\right)$. These corrosion processes can be separated into an initiation and propagation stage. During the initiation stage the corrosion rate is comparatively low as breakdown of the surface oxide occurs. However, once this has happened and repair of the oxide is no longer possible, then the propagation phase results in the rapid consumption of the alloy. Since the coating provides for the repair of the protective surface oxide scales, the initiation stage can be extended, ideally for the design life of the component. However, once coating penetration occurs, the propagation stage often results in catastrophic corrosion rates.

As a background to the development of protection coating technology, the corrosion performance of a wide range of diffusion and overlay coatings, under high temperature oxidation and type I and type II hot corrosion conditions have been extensively reviewed (Nicholls et al., 1990; Nicholls, 2000). The platinum-modified aluminides performed exceptionally well under high temperature oxidation conditions and in type I hot corrosion environments but performed less well under type II hot corrosion conditions, although outperforming conventional aluminides (Nicholls et al., 1990). Of the other diffusion coatings, the silicon-containing diffusion aluminides (for example Sermetel 1515) perform well under type II hot corrosion conditions. Chromised and chrome-aluminised coatings also offer protection under type II corrosion conditions. Thus, silicon containing or chromium-rich diffusion coatings offer improved corrosion resistance at the lower temperatures that are often encountered within utility turbine environments (Nicholls et al., 1990; Luthra \& LeBlanc, 1987). Overlay coatings of classic design, with $18-22 \% \mathrm{Cr}$ and $8-12 \% \mathrm{Al}$, generally perform better at higher temperatures where oxidation is the dominant failure mode (above $900^{\circ} \mathrm{C}$ ) reflecting the good adherence of the thin alumina scales, which is promoted by the presence of active elements such as yttrium. Generally under this high temperature oxidizing conditions NiCrAlYs and NiCoCrAlYs out-perform the cobalt-based systems. However, at low temperatures where type II hot corrosion predominates, corrosion rates for the NiCrAlY and NiCoCrAlY overlay coatings can be relatively high. CoCrAlYs generally outperform NiCrAlY-based systems, with the high chromium containing CoCrAlYs showing best performance (Nicholls et al., 1990; Nicholls, 2000; Novak, 1994). This is illustrated schematically in Fig. 18 reproduced from a paper by Novak (Novak, 1994). Several methods have been investigated to improve the traditional MCrAlY coatings by use of a platinum underlayer and overlayers (Nicholls et al., 2002). Other additions such as Ti, Zr, Hf, Si and Ta have been examined (Saunders \& Nicholls, 1984). Surface modification results in the formation of a duplex coating structure and this can result in improved performance, for example, a pulse-aluminized CoNiCrAlY coating exhibits superior corrosion resistance at 750 and $850^{\circ} \mathrm{C}$ compared to its plasma sprayed counterpart (Nicholls et al., 1990; Nicholls, 2000). Some overlay coating is formed by a gas phase diffusion treatment of a plasma sprayed MCrAlY coating. Silicon modifications to the surface of CoCrAlY coatings have also been proposed and improve the resistance to low temperature hot corrosion (Nicoll, 1984). 


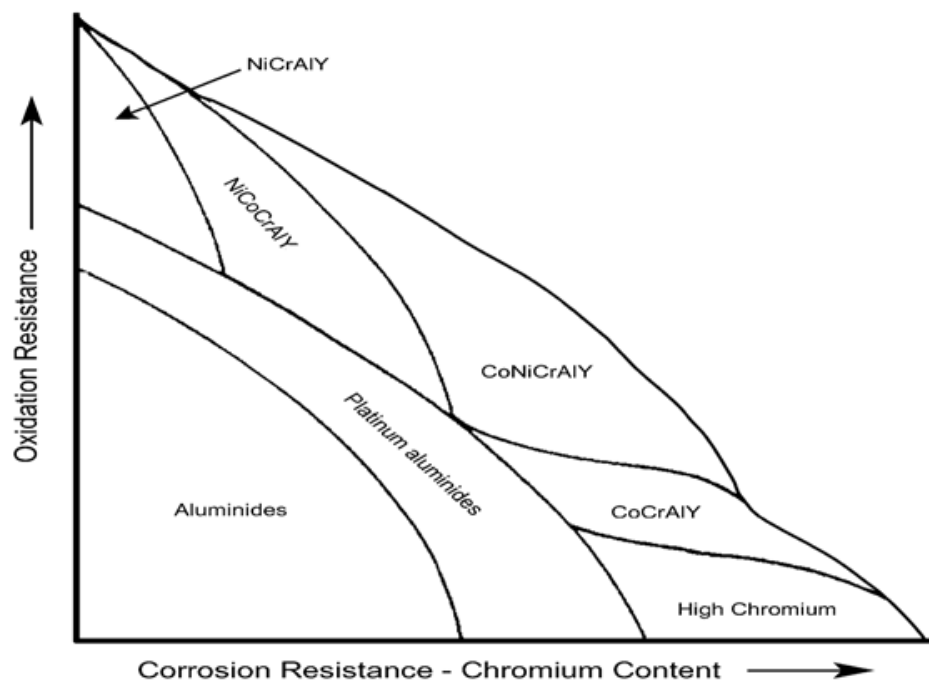

Fig. 18. Schematic representation of rate-temperature curves for Type II hot corrosion, Type I hot corrosion and oxidation (alumina former).

Two categories of coatings arise: diffusion coatings and overlay coatings. Overlay coating involves the application of coatings to substrates using physical deposition processes. Typical application methods include: thermal spraying, physical vapor deposition (PVD), electron beam physical vapor deposition (EBPVD), ion plating/sputtering and electroplating (Stringer, 1987). Overlay coatings typically comprise $\beta+\gamma^{\prime}$ aluminide in a $\gamma$ matrix (Sims et al., 1987) and are of typical composition (Ni, Co)-15-28 wt.\% Cr, 4-18 wt.\% $\mathrm{Al}, 0.5-0.8$ wt.\% Y (Goward, 1998). The relative amounts of $\mathrm{Ni}$ and Co depend upon: (a) coating ductility requirements $(>\mathrm{Ni})$ and $(\mathrm{b})$ corrosion resistance $(>\mathrm{Co})$. The excellent oxidation and corrosion resistance of the coatings is afforded by the formation of highly adherent alumina scales which grow slowly as a result of the reactive element effect attributable to yttrium. In addition, their high $\mathrm{Cr}$ contents make them useful protective coatings against Type II hot corrosion. These overlay coatings are deposited using thermal spray (Ar shrouded plasma (APS) or low pressure plasma (LPPS)) techniques or EBPVD). The EBPVD technique is typically preferred for high quality coatings since a certain amount of oxidation of the coating particles typically occurs during thermal spraying giving rise to nanoscale oxide particles at splat boundaries. However, the thermal spray processes are frequently used in practice.

Overlay coatings show interdiffusion effects with alloy substrates and Itoh and Tamura indicate the rate of interdiffusion decreases in the order NiCrAlY $>$ CoCrAlY $>$ NiCoCrAlY $>$ CoNiCrAlY, where NiCo represents higher Ni contents compared to Co and CoNi higher Co contents (Itoh \& Tamura, 1999). These results, collected using vacuum plasma sprayed coatings were independent of the three substrates used in the experimental program. The most recent technological advance in overlay coating technology is the development of socalled smart coatings (Nicholls et al., 2002). These coatings attempt to address the problems associated with the differences in temperature over the surface of an airfoil. Temperatures 
vary from a maximum of the order of $1100^{\circ} \mathrm{C}$ at leading and trailing edges to about $650{ }^{\circ} \mathrm{C}$ in the center of the airfoil surfaces and near airfoil roots. Because of this, the nature of environmental degradation varies from oxidation through Type I hot corrosion to Type II hot corrosion as indicated in Fig. 17. A practical example of this variation in corrosion type with temperature is graphically portrayed by Viswanathan in his analysis of the failure of airfoils (Viswanathan, 2001). Following extensive laboratory studies employing alkali-metal sulphates in simulated gaseous environments, Nicholls et al. have been able to very carefully define optimized chromium and aluminium contents for oxidation and corrosion protection in the temperature ranges referred to above (Nicholls et al., 2002). As might be expected, high $\mathrm{Cr}$ contents (>40 wt.\%) and low Al contents (6-8 wt.\%) are most suitable for protection from Type II hot corrosion. For protection from Type I hot corrosion, roughly equal amounts of $\mathrm{Cr}$ and $\mathrm{Al}$ represent optimized compositions. Oxidation protection $\left(1100^{\circ} \mathrm{C}\right)$, is best afforded by coatings containing $25 \mathrm{wt.} \% \mathrm{Cr}$ and $14 \mathrm{wt} \% \mathrm{Al}$. The final coating developed by Nicholls et al. comprises a commercial base coating (Co-32Ni-21Cr8Al-0.5Y) adjacent to the substrate, a $\mathrm{Cr}$ enriched layer of variable composition from $\mathrm{Ni}$ 60Cr-20Al to Ni-35Cr-40Al and a surface layer of composition Ni-15Cr-32Al (Nicholls et al., 2002). These multi-layer coatings have been shown to outperform typical a commercial $\mathrm{Pt}$ modified aluminide and an $\mathrm{Al}$ enriched version of the base coat at $700-800{ }^{\circ} \mathrm{C}$. Whilst this technology appears a step forward, issues related to coating ductility and additional improvements afforded by cobalt with respect to corrosion resistance, may be of additional importance.

\section{Conclusions}

In this work, the thermal degradation behavior of selected CoNiCrAlY coatings has been studied. Isothermal oxidation behaviors of the VPS MCrAlY metallic overlay coatings were observed for comparative study. Coatings were oxidized isothermally at a $1273 \mathrm{~K}$ for different time periods in order to form the thermally grown oxide layer. Particular focus is set on the influence of particle size, chemical composition, and exposure time on the oxygen content in coatings, porosity, surface roughness, and TGO growth.

The particle size has a significant effect on the oxidization of the in-flight particle and consequently the oxygen content in the as-sprayed coatings. But after thermal exposure, the difference of the oxygen contents between the smaller and larger particle coatings was decreased with increasing exposure time. The distribution of particle size plays the important role of porosity than only the particle size. It can be found that using the trimodal arrangement in the mixture with different diameters of the large, middle and small spheres can obtain the highest deposition density. In some cases, the unmelted particles press the splats and make the poorly bonded splat-splat contact closed.

The isothermal degradation of coatings was considerably influenced by the heat exposure time. The porosity decreased gradually in all coatings with increasing exposure time, but in view of details, the porosity decreased at Stage $\mathrm{I}_{\mathrm{P}}(0-10$ or $0-1 \mathrm{~h})$, and increased at Stage $\mathrm{II}_{\mathrm{P}}$ (10-100 or $1-10 \mathrm{~h})$, and then finally decreased again over Stage $\mathrm{II}_{\mathrm{P}}$. These could be due to the sintering effect at Stage $I_{P}$, which leads to heal cracks and lock splats together. The surface roughness decreased up to Stage $I_{R}$ with increasing exposure time, but over Stage $I_{R}$, surface 
roughness was kept in relatively fixed value or increased slightly. The TGO thickness growth rate and parabolic oxidation rate constant are influenced by the surface roughness of coatings with increasing heat exposure time.

\section{Acknowledgment}

The authors would like to express thanks to Mr. S. Murata at Murata Boring Technology Research Co., Japan for the financial support of this work. Authors also thank Mr. M. Tanno for assisting in coating characterization.

\section{References}

Birks, N. \& Meier, G.H. (1983). Introduction to High Temperature Oxidation of Metals, Edward Arnold, ISBN 978-0713134643, London, UK

Brandl, W., Grabke, H.J., Toma, D., \& Kruger, J. (1996). The Oxidation Behaviour of Sprayed MCrAlY Coatings. Surf. Coat. Technol., Vols.86-87, No.1, (December 1996), pp. 41-47, ISSN 0257-8972

Choi, H., Yoon, B., Kim, H., \& Lee, C. (2002). Isothermal Oxidation of Air Plasma Spray NiCrAlY Bond Coatings. Surf. Coat. Technol., Vol.150, Nos.2-3, (February 2002), pp. 297-308, ISSN 0257-8972

Dobler, K., Kreye, H., \& Schwetzke, R. (2000). Oxidation of Stainless Steel in the High Velocity Oxy-Fuel Process. J. Therm. Spray Technol., Vol.9, No.3 (September 2000), pp. 407-413, ISSN 1059-9630

Eliaz, N., Shemesh, G., Latanision, R.M. (2002). Hot Corrosion in Gas Turbine Components. Eng. Fail. Anal., Vol.9, No.1, (February 2002), pp. 31-43, ISSN 1350-6307

Espie, G., Fauchais, P., Labbe, J.C., Vardelle, A., \& Hannoyer, B. (2001). Oxidation of Iron Particles during APS: Effect of the Process on Formed Oxide Wetting of Droplets on Ceramics Substrates. Proceedings of ITSC 2001: New Surfaces for a New Millennium, pp. 821-827, ISBN 978-0871707376, Singapore, May 28-30, 2001

Fukushima, T. \& Kuroda, S. (2001). Oxidation of HVOF Sprayed Alloy Coatings and Its Control by a Gas Shroud. Proceedings of ITSC 2001: New Surfaces for a New Millennium, pp. 527-532, ISBN 978-0871707376, Singapore, May 28-30, 2001

Goward, G.W. (1998). Progress in Coatings for Gas Turbine Airfoils. Surf. Coat. Technol., Vols.108-109, (October 1998), pp. 73-79, ISSN 0257-8972

Itoh, Y., Tamura, M. (1999). Reaction Diffusion Behaviors for Interface Between Ni-Based Super Alloys and Vacuum Plasma Sprayed MCrAlY Coatings. J. Eng. Gas. Turb. Power, Vol.121, No.3, (July 1999), pp. 476-483, ISSN 0742-4795

Khanna, A.S. (2004). Introduction to High Temperature Oxidation and Corrosion, ASM International, ISBN 0-87170-762-4, Materials Park, OH, USA

Kulkarni, A., Vaidya, A., Goland, A., Sampath, S., \& Herman, H. (2003). Processing Effects on Porosity-property Correlations in Plasma Sprayed Yttria-stabilized Zirconia Coatings. Mater. Sci. Eng. A, Vol.359, Nos.1-2, (October 2003), pp. 100-111, ISSN 0921-5093 
Li, C.J. \& Li, W.Y. (2003). Effect of Sprayed Powder Particle Size on the Oxidation Behavior of MCrAlY Materials during High Velocity Oxygen-fuel Deposition. Surf. Coat. Technol., Vol.162, No.1, (January 2003), pp. 31-41, ISSN 0257-8972

Luthra, K.L. \& LeBlanc, O.H. (1987). Low temperature hot corrosion of CoCrAl alloys. Mater. Sci. Eng., Vol.87, No.C, (March 1987), pp. 329-335, ISSN 0025-5416

Neiser, R.A., Smith, M.F., \& Dykhuizen, R.C. (1998). Oxidation in Wire HVOF-Sprayed Steel. J. Therm. Spray Technol., Vol.7, No.4, (December 1998), pp. 537-545, ISSN 1059-9630

Nicholls, J.R. \& Saunders, S.R.J. (1990). High Temperature Materials for Power Engineering, Kluwer, ISBN 978-0792309277, Dordrecht, Netherlands

Nicholls, J.R. (2000). Designing Oxidation-Resistant Coatings. JOM, Vol.52, No.1, (January 2000), pp. 28-35, ISSN 1543- 1851

Nicholls, J.R., Simms, N.J., Chan, W.Y., Evans, H.E. (2002). Smart overlay coatings - concept and practice. Surf. Coat. Technol., Vol.149, Nos.2-3, (January 2002), pp. 236-244, ISSN 0257-8972

Nicoll, A.R. (1984). Coatings and Surface Treatment for Corrosion and Wear Resistance, Ellis Horwood, ISBN 978-0131400962, Chichester, UK

Novak, R.C. (1994). Coatings Development and Use: Case Studies, Presentation to the Committee on Coatings for High-Temperature Structural Materials, National Materials Advisory Board, National Research Council, Irvine, California, US

Pint, B.A. (1996). Experimental Observations in Support of the Dynamic-segregation Theory to Explain the Reactive-element Effect. Oxid. Met., Vol.45, Nos.1-2, (February 1996), pp. 1-37, ISSN 1573-4889

Pomeroy, M.J. (2005). Coatings for Gas Turbine Materials and Long Term Stability Issues. Mater. Des., Vol.26, No.3, (May 2005), pp. 223-231, ISSN 0264-1275

Ray, A.K., Roy, N., \& Godiwalla, K.M. (2001). Crack Propagation Studies and Bond Coat Properties in Thermal Barrier Coatings under Bending. Bull. Mater. Sci. , Vol.24, No.2, (April 2001), pp. 203-209, ISSN 0250-4707

Ray, A.K. \& Steinbrech, R.W. (1999). Crack Propagation Studies of Thermal Barrier Coatings under Bending. J. Eur. Ceram. Soc., Vol.19, No.12, (October 1999), pp. 2097-2109, ISSN 0955-2219

Saunders, S.R.J. \& Nicholls, J.R. (1984). Hot Salt Corrosion Test Procedures and Coating Evaluation. Thin Solid Films, Vol.119, No.3, (September 1984), pp. 247-269, ISSN 0040-6090

Sims, C.T., Stoloff, N.S., Hagel, W.C. (1987). Superalloys II, Wiley, ISBN 978-0471011477, New York, USA

Stringer, J. (1987). Role of Coatings in Energy-producing Systems: an Overview. Mater. Sci. Eng., Vol.87, (March 1987), pp. 1-10, ISSN 0025-5416

Tang, F., Ajdelsztajn, L., Kim, G.E., Provenzano, V., \& Schoenung, J.M. (2004). Effects of Surface Oxidation during HVOF Processing on the Primary Stage Oxidation of a CoNiCrAlY Coating. Surf. Coat. Technol., Vol.185, No.2-3, (July 2004), pp. 228-233, ISSN 0257-8972 
Thompson, J.A. \& Clyne, T.W. (2001). The Effect of Heat Treatment on the Stiffness of Zirconia Top Coats in Plasma-Sprayed TBCs. Acta Mater., Vol.49, No.9, (May 2001), pp. 1565-1575, ISSN 1359-6454

Viswanathan, R. (2001). An Investigation of Blade Failure in Combustion Turbines. Eng. Fail. Anal., Vol.8, No.5, (October 2001), pp. 493-511, ISSN 1350-6307

Volenik, K., Novak, V., Dubsky, J., Chraska, P., \& Neufuss, K. (1997) Properties of Alloy Steel Coatings Oxidized during Plasma Spraying, Mater. Sci. Eng. A, Vols.234-236, No.30, (August 1997), pp. 493-496, ISSN 0921-5093 


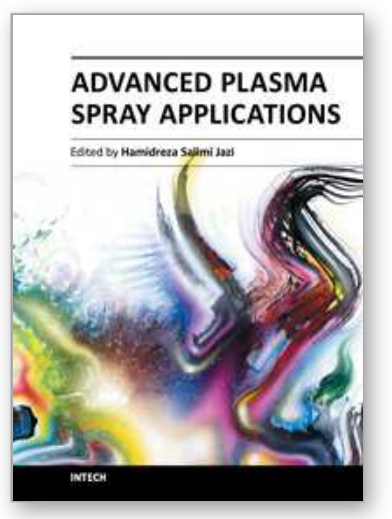

\author{
Advanced Plasma Spray Applications \\ Edited by Dr. Hamid Jazi
}

ISBN 978-953-51-0349-3

Hard cover, 250 pages

Publisher InTech

Published online 21, March, 2012

Published in print edition March, 2012

Recently, plasma spray has been received a large number of attentions for various type of applications due to the nature of the plasma plume and deposition structure. The plasma gas generated by the arc, consists of free electrons, ionized atoms, some neutral atoms, and undissociated diatomic molecules. The temperature of the core of the plasma jet may exceed up to $30,000 \mathrm{~K}$. Gas velocity in the plasma spray torch can be varied from subsonic to supersonic using converging-diverging nozzles. Heat transfer in the plasma jet is primarily the result of the recombination of the ions and re-association of atoms in diatomic gases on the powder surfaces and absorption of radiation. Taking advantages of the plasma plume atmosphere, plasma spray can be used for surface modification and treatment, especially for activation of polymer surfaces. I addition, plasma spray can be used to deposit nanostructures as well as advanced coating structures for new applications in wear and corrosion resistance. Some state-of-the-art studies of advanced applications of plasma spraying such as nanostructure coatings, surface modifications, biomaterial deposition, and anti wear and corrosion coatings are presented in this book.

\title{
How to reference
}

In order to correctly reference this scholarly work, feel free to copy and paste the following:

Dowon Seo and Kazuhiro Ogawa (2012). Isothermal Oxidation Behavior of Plasma Sprayed MCrAlY Coatings, Advanced Plasma Spray Applications, Dr. Hamid Jazi (Ed.), ISBN: 978-953-51-0349-3, InTech, Available from: http://www.intechopen.com/books/advanced-plasma-spray-applications/isothermal-oxidation-behavior-of-theplasma-sprayed-mcraly-coatings

\section{INTECH}

open science | open minds

\section{InTech Europe}

University Campus STeP Ri

Slavka Krautzeka 83/A

51000 Rijeka, Croatia

Phone: +385 (51) 770447

Fax: +385 (51) 686166

www.intechopen.com

\section{InTech China}

Unit 405, Office Block, Hotel Equatorial Shanghai

No.65, Yan An Road (West), Shanghai, 200040, China 中国上海市延安西路65号上海国际贵都大饭店办公楼405单元

Phone: +86-21-62489820

Fax: $+86-21-62489821$ 
(C) 2012 The Author(s). Licensee IntechOpen. This is an open access article distributed under the terms of the Creative Commons Attribution 3.0 License, which permits unrestricted use, distribution, and reproduction in any medium, provided the original work is properly cited. 